\title{
Ceramic tiles adding waste foundry sand to different clays
}

\author{
N. E. Quaranta ${ }^{1}$, N. S. Lalla ${ }^{1}$, M. G. Caligaris ${ }^{1}$, A. R. Boccaccini ${ }^{2}$ \\ \& C. M. Vieira ${ }^{3}$ \\ ${ }^{1}$ Universidad Tecnológica Nacional, Argentina \\ ${ }^{2}$ Department of Materials Science and Engineering, \\ University of Erlangen-Nuremberg, Germany \\ ${ }^{3}$ Universidade Estadual do Norte Fluminense Darcy Ribeiro - UENF, \\ Brazil
}

\begin{abstract}
This work continues the research on recycling of waste foundry sand as aggregate in the manufacture of bricks and red clay tiles. Initially, clay with a major content of soil was used. The obtained specimens showed high porosity due to the combustion of the organic matter present. Moreover, this type of raw material has properties that vary greatly according to the extraction sites.

In order to improve quality and achieve uniformity in the properties of the obtained products, samples with commercial clay in similar composition are studied in this work. The commercial clay (from Olavarría, Argentina) is composed of a mixture of mineral clays without any content of black soil.

Several samples were obtained with aggregates of different percentages of foundry sand to the commercial clay, with a compaction pressure of $25 \mathrm{MPa}$. These samples were heat treated to $930^{\circ} \mathrm{C}$ for three hours.

The characterization of raw materials and products was carried out by using different techniques: optical and scanning electron microscopies, porosity and density measurements and mechanical properties determination, among others. The results were analyzed on a comparative basis with those of samples produced from clays containing black soil.

The obtained materials meet the standards required for commercial products. Keywords: recycling, construction materials, foundry sand, red clay.
\end{abstract}




\section{Introduction}

The correct use of natural resources, so that they last a long time, along with the use of other resources, such as industrial discards through recycling, is of fundamental importance for the conservation of the environment, allowing further reduction in energy consumption and pollutant emissions compared to traditional processes.

This work continues the research already conducted on the recycling of waste foundry sand of the iron melting process, as aggregate in the manufacture of bricks and tiles of red clay for use in civil construction. The studied waste comes from a metallurgical industry located in the southern region of Santa Fe Province. This industrial discard, foundry sand, has been studied by several authors from the point of view of their characterization, mainly in order to analyze the risk of its disposal in landfills, with particular emphasis on evaluating the content of process additives, and leaching compounds [1-5]. Some authors have studied the replacement of sand in concrete mixes by waste foundry sands in content up to $30 \%[6,7]$, the use of foundry sand in the construction of troughs of blast furnaces [8] and as aggregates in ceramic formulations [9].

In previous work [10] clay with a major content of soil was used, as is customary in traditional brickworks. The obtained pieces showed high porosity due to the combustion of the organic matter present. Losses of weight and shrinkage of the samples during firing, with the formation of microcracks in the clay matrix, were observed. Moreover, this type of raw material has properties that vary greatly according to the extraction sites. As well as these disadvantages in the obtained product, the environmental viewpoint should not be forgotten since the places of extraction of these clays lose soil fertility.

In order to improve quality and achieve uniformity in the properties of the products obtained in this study, similar samples with commercial clay composed of a mixture of clay minerals without soil content were analyzed.

\section{Experimental}

\subsection{Sample preparation}

The raw materials used for the preparation of the samples were foundry sand waste from a Santa Fe metallurgical industry, and commercial clay from quarries in the area of Olavarría, in Buenos Aires Province, consisting of a mixture of clay minerals without black soil.

Mixtures were prepared with $0,10,20,30,40$ and 50\% of foundry sand with a moisture content of $8 \%$. The different samples were formed in a mold of approximately $40 \mathrm{~mm} \times 70 \mathrm{~mm}$ with an applied pressure of $25 \mathrm{MPa}$ for one minute and then were dried at room temperature for 4 days before sintering, simulating industrial manufacture conditions.

The samples were heat treated. The treatment consisted of heating to $930^{\circ} \mathrm{C}$, maintaining this temperature for 3 hours. Finally the samples were cooled to room temperature inside the oven. Taking into account the steps and the heating 
and cooling velocities, the samples remained for more than 6 hours over $900^{\circ} \mathrm{C}$. The determination of the maximum treatment temperature was conducted using ternary diagrams, taking into account the chemical compositions of the materials, the major components of mixtures $\left(\mathrm{SiO}_{2}, \mathrm{Al}_{2} \mathrm{O}_{3}\right.$ and $\left.\mathrm{Fe}_{2} \mathrm{O}_{3}\right)$ and the presence of $\mathrm{Na}$ and $\mathrm{K}$, which act as fluxes. The heating rate was not constant, but adequate to that used in the brick industry in the area (about $2^{\circ} \mathrm{C} / \mathrm{min}$ in the whole process, and $0.8^{\circ} \mathrm{C} / \mathrm{min}$ in the range $550-750^{\circ} \mathrm{C}$, corresponding to the displacive transformation of quartz).

\subsection{Characterization of raw materials and products}

The powders to be used as raw material for the bricks production and the fired samples obtained were characterized by several techniques: optical and scanning electron microscopies (SEM), electron diffraction analysis X-ray (EDAX), particle size distribution, porosity, mechanical properties and emissions analysis.

The obtained sintered bodies were prepared for characterization. Pieces of about $1 \mathrm{~cm}^{3}$ were cut, squeezed in resin and then polished with different papers and pastes (up to diamond $1 \mu \mathrm{m}$ ) in order to reach a proper surface for microscopic observations.

The optical observations were made with Zeiss-Axiotech equipment with a Donpisha 3CCD camera and image scanner.

The SEM analyses were carried out through a Phillips 515 scanning electronic microscope with an X-ray detector (EDAX-Phoenix).

The porosity of the samples was determined by the 12510 IRAM Standard.

The mechanical essays were carried out with a Cific Universal Testing Machine, $294 \mathrm{kN}$. The bending test is performed on samples with the aspect ratio established in ASTM C67-03a Standard.

The calcination process of raw materials has been characterized also through analysis of emissions in relation to the presence of combustion gases and particulate matter emitted. The determined gases were nitrogen oxides (NOx), sulphur dioxide $\left(\mathrm{SO}_{2}\right)$, carbon monoxide $(\mathrm{CO})$ and hydrocarbons $(\mathrm{HC})$. The particulate matter was analyzed according to air quality standards as PM10 (particles size less than $10 \mu \mathrm{m}$ ). For this analysis EPA2001 XILIX air quality equipment with electrochemical sensors for gases and laser radiation chamber for particulate matter was used. The determined values are compared with the thresholds regulated (Decree 3395/96, Law 5965, modified by Resolution 242/97, Provincial Agency for Sustainable Development, Argentina).

\section{Results and discussion}

The semi-quantitative chemical analysis by EDS on raw materials, determined the compositions expressed as simple oxides. These compositions are detailed in Table I.

It is important to note that the analysis of these samples was performed on the original materials, without grinding. For this reason the chemical composition of the foundry sand actually reflects the composition of the surface area of the 
Table 1: $\quad$ EDS analysis of wastes and clay.

\begin{tabular}{|c|c|c|c|c|c|c|c|c|c|}
\hline & \multicolumn{9}{|c|}{ Oxides [\%] } \\
\hline & $\mathrm{Na}_{2} \mathrm{O}$ & MgO & $\mathbf{A l}_{2} \mathbf{O}_{3}$ & $\mathrm{SiO}_{2}$ & $\mathbf{K}_{2} \mathbf{O}$ & $\mathrm{CaO}$ & $\mathrm{TiO}_{2}$ & $\mathrm{FeO}$ & MnO \\
\hline Sand & 5,2 & 4,4 & 14,7 & 70,1 & 0,3 & 0,7 & --- & 4,4 & 0,2 \\
\hline Soil & 5,0 & 3,7 & 18,0 & 67,1 & 1,6 & 0,9 & 0,5 & 3,2 & --- \\
\hline Clay & --- & 3,0 & 18,7 & 63,3 & 4,8 & 1,1 & 0,8 & 8,3 & --- \\
\hline
\end{tabular}
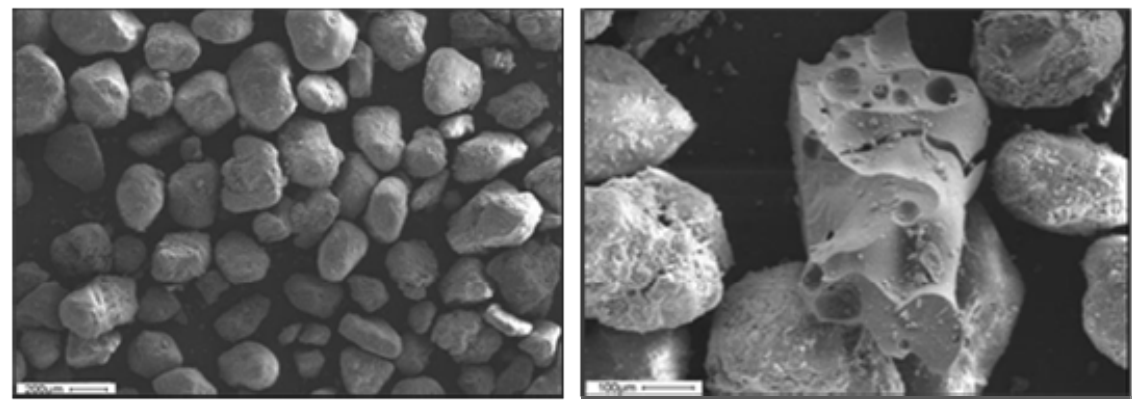

Figure 1: $\quad$ Particles of metallurgical waste.

particles coming from the molds used, containing bentonite added during the manufacturing process of the molds. For comparison purposes, the percentage composition of the raw materials of Table 1 is expressed as oxides. Expressed in this way it can be seen that the compositions of the common clay (soil) and the commercial clay are similar with a slightly higher presence of iron oxides in commercial and fluxes $(\mathrm{Na}, \mathrm{K})$ in the common clay. However, element analysis which also includes $\mathrm{C}$ indicates the presence of approximately $15 \%$ for the case of soil, while for the commercial clay that element is not detected.

Figure 1 shows SEM micrographs of the sample of foundry sand. It can be seen that it has quite a homogeneous distribution in size, compact rounded particles without the presence of marked edges or angles. The presence of small proportions of different grains can be noted, with the appearance of molten phases, which were analyzed by EDS and found to be composed of $\mathrm{Si}, \mathrm{Ca}$ and $\mathrm{O}$, assuming them as calcium silicate [10].

Figure 2 shows the microscopic appearance of clay material. It presents a homogeneous distribution of particles, but some larger particles can also be found. The size distribution analysis of this commercial clay shows that over $70 \%$ of the material is smaller than $75 \mu \mathrm{m}$.

In order to determine the potential emissions of gases and particulate matter, the calcination process of raw materials has been carried out on the waste and the two clays, resulting in maximum emission values that are well below the thresholds regulated, which are for example $0.150 \mathrm{mg} / \mathrm{m}^{3}(24 \mathrm{~h} /$ average) for PM10 and 9 ppm (8h/average) for CO. 

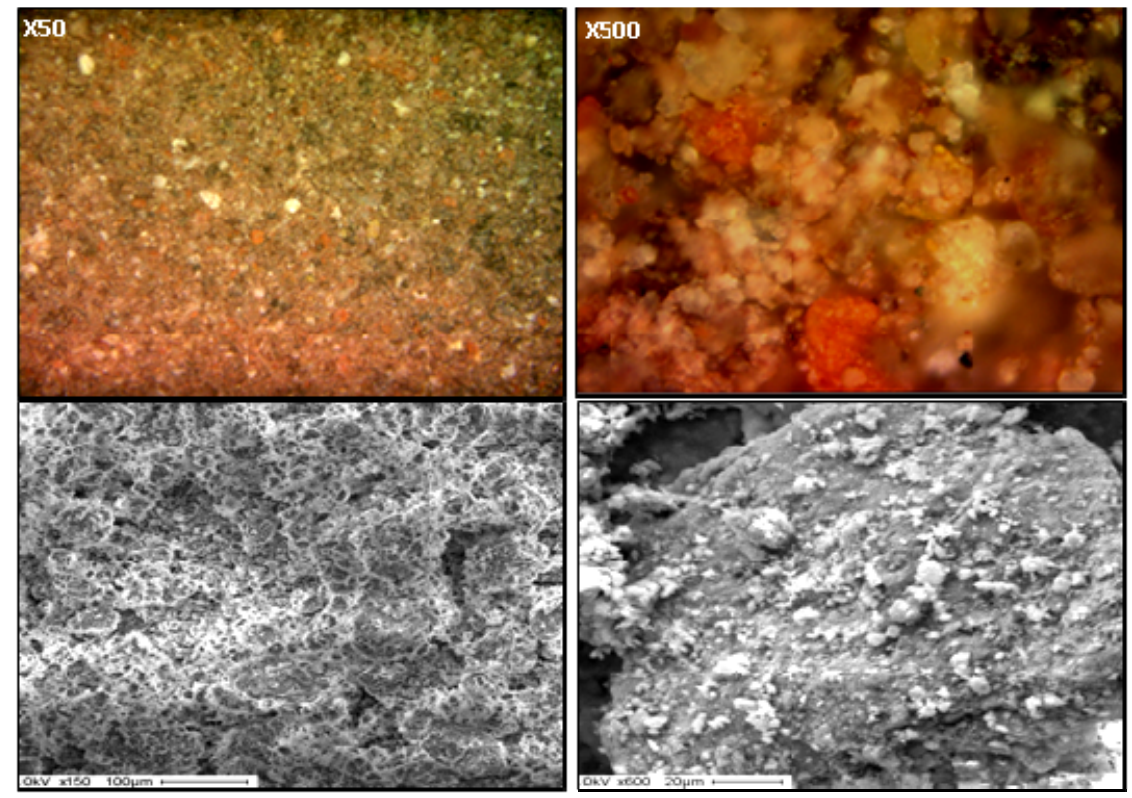

Figure 2: Optical and SEM micrographs of commercial clay.

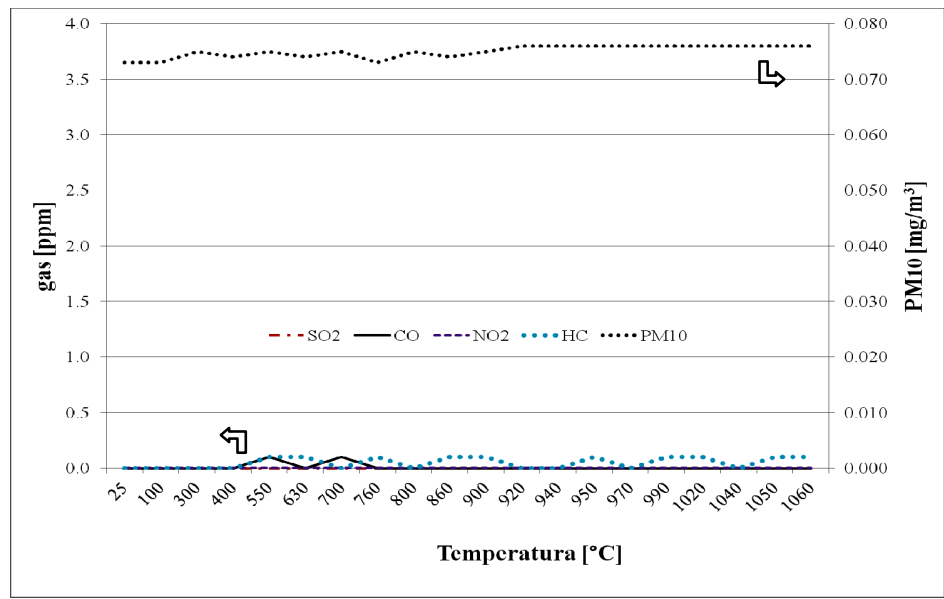

Figure 3: $\quad$ Gas and PM10 emissions for soil samples.

Figure 3 shows the emissions measured during de combustion of soil samples. The results of these analyses for the commercial clay indicate that this material has no exhaust emissions, and the particulate matter emission is negligible. In the case of foundry sand sample, the particulate matter emission was similar to that of soil sample. In relation to gas analyses, $\mathrm{CO}$ and $\mathrm{HC}$ emissions were observed, 


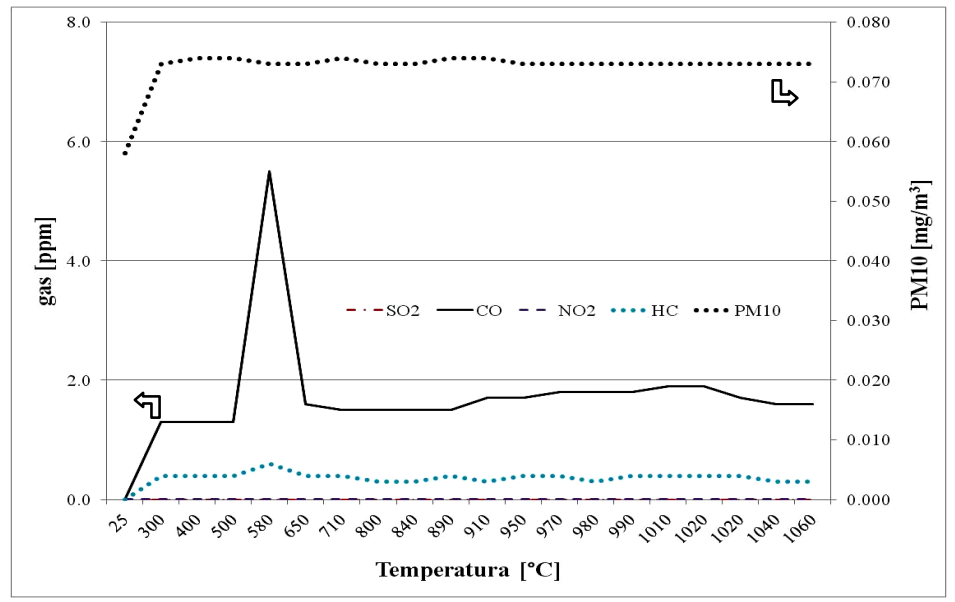

Figure 4: $\quad$ Gas and PM10 emissions for sand samples.

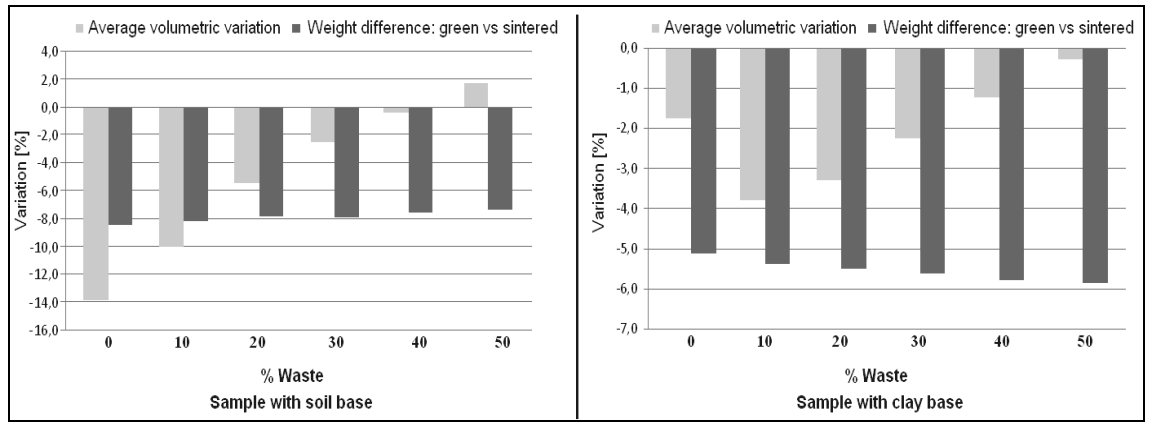

Figure 5: Volumetric variation and weight loss of the samples.

with maximum values at $550^{\circ} \mathrm{C}$, which have been attributed to the combustion of organic substances used during the molds pressing process. However, as mentioned, their values are below the maximum levels regulated.

In its macroscopic appearance all the samples produced with commercial clay are compact, with an intense red color, with defined edges, without shelling of the structure, indicating that they have achieved a remarkable degree of sintering, without reaching temperatures close to the vitreous phase formation of main oxides, which would be observed as loss of edges and vertices. In previous experiences with common clay, although similar features were reached, samples with $50 \%$ of foundry sand showed mass loss by shelling during the cutting and polishing, even though the maximum temperature of treatment in these samples was $1000^{\circ} \mathrm{C}$.

The measured values of permanent linear expansion, expressed as volume change in percentage, and weight loss on ignition, expressed as a percentage, are presented in Figure 5, in graphics for commercial and common clay (soil) [10]. It 


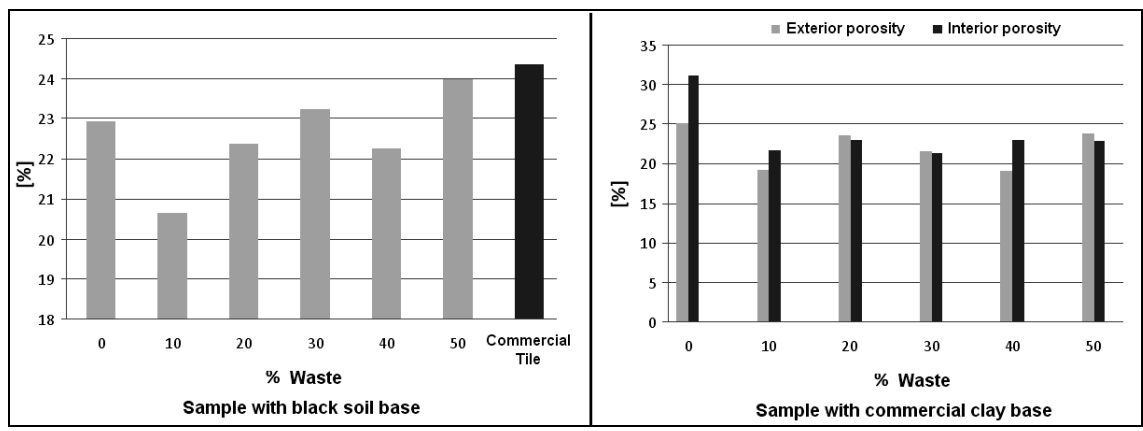

Figure 6: Porosity of the samples.

is possible to observe a clear trend of the samples to contract due to the sintering, process much more pronounced in the case of common clay, where the reference samples without waste content, show a contraction of about $14 \%$ in volume.

The weight loss on ignition of the samples (which includes part of the water added during forming, as it relates to green compact, dried at room temperature and humidity), rounds $8 \%$ for common clay and does not reach the $6 \%$ in samples with commercial clay.

In samples with commercial clay however it can be observed that weight loss tends to increase with increasing residual sand content of the samples. This fact can be explained taking into account the weight loss on ignition of the materials separately. They are similar in the case of waste and soil, $5.6 \%$ and $5.7 \%$ respectively and much lower for the commercial clay $(0.6 \%)$.

The apparent porosity of the samples is presented in the graphs of Figure 6. In the case of common clay, there is a trend to higher porosity as the content of waste is higher, reaching approximately $24 \%$ porosity for samples with $50 \%$ foundry sand addition, a value similar to that determined for a commercial product with similar characteristics. In the case of samples produced with commercial clay, porosity values of the same order were determined, between 19 and $24 \%$, without significant variations between internal and external areas of the samples.

The mechanical properties tested, compressive strength and flexural modulus of rupture of the compact sintered samples are presented in the graphs of Figure 7. Comparing samples with equal waste content, higher mechanical strength has been determined in samples produced with commercial clay than in the samples with common clay. It is also seen that the values of these properties analyzed in every case, tend to decrease as the waste additions are higher.

Microscopic observations of the samples, show a homogeneous distribution of residual sand grains, regardless of the content of waste and the area of the sample being observed, namely in areas close to the sample surface or in its internal areas. In the samples obtained from common clay, a heterogeneous distribution of grains when residues were greater than $30 \%$ was observed, with a tendency to form clusters of residual material in the central area of the tiles. This can be seen 


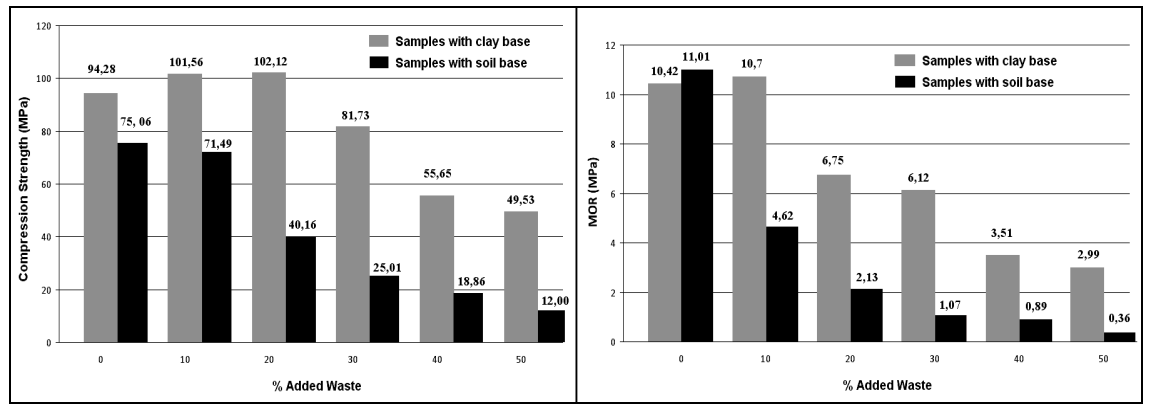

Figure 7: $\quad$ Compressive strength and modulus of rupture of the samples.
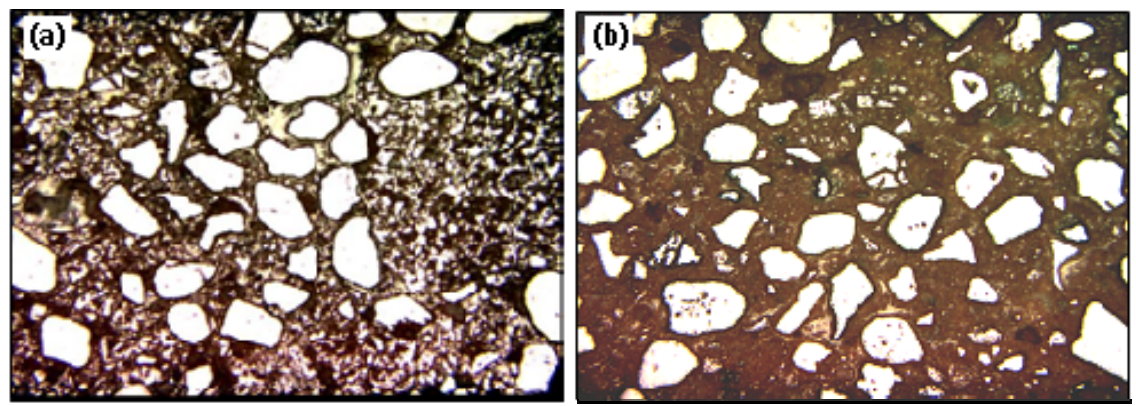

Figure 8: Optical micrographs of the samples with 50\% waste. Magnification: X50 (a) common clay; (b) commercial clay.
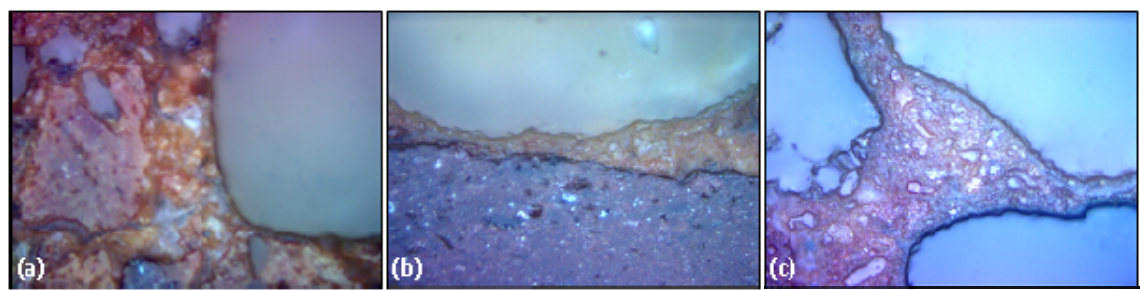

Figure 9: $\quad$ Sand grain and big clay particles incorporated in the matrix. (a) $30 \%$, (b) $40 \%$, and (c) $50 \%$ waste in commercial clay. Magnification: X500.

in Figure 8, which shows optical microscope photographs of the various clays, with $50 \%$ added waste.

Figures 9 and 10 show optical photographs made during the analysis of the samples in order to determine the degree of incorporation of the residual sand particles in the clay material used for the case of commercial and common clay respectively. When the base material is commercial clay, all samples including $50 \%$ of added waste, show a high degree of binding and incorporation of sand into the matrix of the brick, which presents a significant degree of sintering. The 

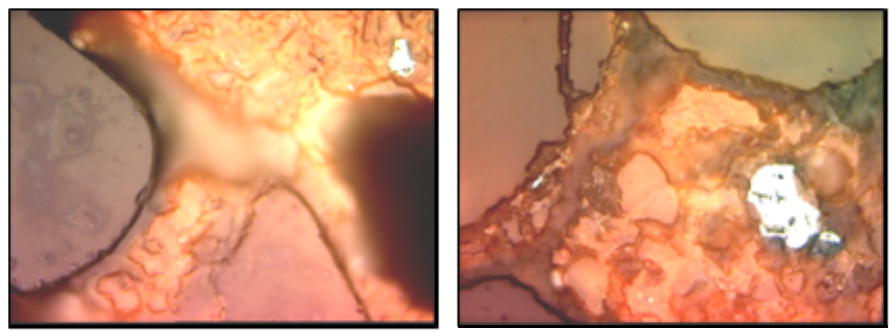

Figure 10: Micrographs of a sample with $50 \%$ sand in common clay. Magnification: X500.

samples previously studied with soil as base material (Figure 10), have developed a more localized porosity at the edges of sand grains, and microcracks at the clay matrix, an effect that becomes more remarkable with increasing percentage of residual sand added.

\section{Conclusions}

The results of these studies on the incorporation of waste foundry sands to two different types of clay have confirmed the feasibility of reusing this metallurgical waste as raw material in the ceramic industry for civil constructions. The use of commercial clay instead of common clay (black soil) has led to compact sintered products with better properties for use in service. The presented approach allows the incorporation of significant amounts of residual sand (up to 50\%) with lower sintering temperatures, lower volumetric variations and less weight loss on ignition, achieving further improved mechanical properties (greater resistance to compression and bending).

\section{Acknowledgements}

The authors wish to thank the Commission of Scientific Researchers of Buenos Aires Province, Argentina, and the National Agency of Technological and Scientific Promotion, Argentina, for the financial supports received for this work.

The fulfillment of this work was also possible thanks to the collaboration of the company Paraná Metal (Villa Constitución City, Santa Fe Province, Argentina).

\section{References}

[1] R. Dungan, J. Reeves III., "Pyrolysis of carbonaceous foundry sand additives: Seacoal and gilsonite", Thermochimica Acta, 460, pp. 60-66, (2007). 
[2] Z. Mariachiara, A. Godio, "Recovery of foundry sands and iron fractions from an industrial waste landfill", Resources, Conservation and Recycling, 48, pp. 96-411, (2006).

[3] K. Bastian, J. Alleman, "Microtox characterization of foundry sand residuals", Waste Management, 18, pp. 227-234, (1998).

[4] C. Paluszkiewicz, M. Holtzer, A. Bobrowski, "FTIR analysis of bentonite in moulding sands", Journal of Molecular Structure, 880 [1-3], pp. 109114, (2008).

[5] R. Dungan, N. Dees, "The characterization of total and leachable metals in foundry molding sands", Journal of Environmental Management, 90 [1], pp. 539-548, (2009).

[6] Z. Ismail, E. Al-hashmi, "Reuse of waste iron as a partial replacement of sand in concrete", Waste Management, 28, pp. 2048-2053, (2008).

[7] R. Siddique, G. Schutter, A. Noumowe, "Effect of used foundry sand on the mechanical properties of concrete", Construction and Building Materials, 23, pp. 976-980, (2009).

[8] R. Magnani Andrade, S. Cava, S. Nascimento Silva, L. Bastos Soledade, C. Rossi, E. Leite, C. Paskocimas, J. Varela, E. Longo, "Foundry sand recycling in the troughs of Blast furnaces: a technical note", Journal of Materials Processing Technology, 159, pp. 125-134, (2005).

[9] F. Raupp-Pereira, M. Ribeiro, A. Segadaes, J. Labrincha, "Extrusion and property characterisation of waste based ceramic formulations", Journal of the European Ceramic Society, 27, pp. 2333-2340, (2007).

[10] N. Quaranta, M. Caligaris, H. López, M. Unsen, J. Pasquini, N. Lalla and A. Boccaccini, "Recycling of foundry sand residuals as aggregates in ceramic formulations for construction materials", Ecosystems and Sustainable Development, VII, pp. 503-512, (2009). 